\title{
Plasma methemoglobin as a potential biomarker of anemic stress in humans
}

\section{La méthémoglobine plasmatique: un marqueur potentiel du stress anémique chez l'humain}

\author{
Gregory M. T. Hare, MD, PhD • Alexander Mu, MD • Alexander Romaschin, MD • \\ Albert K.-Y. Tsui, PhD • Nadine Shehata, MD • W. Scott Beattie, MD, PhD • \\ C. David Mazer, MD
}

Received: 8 June 2011/Accepted: 21 December 2011/Published online: 20 January 2012

(C) Canadian Anesthesiologists' Society 2012

\begin{abstract}
Purpose Transfusion of allogeneic red blood cells (RBCs) is one of the main treatments of acute anemia secondary to blood loss and fluid resuscitation within the operating room. Decisions to transfuse blood are based largely on intermediate biological markers (hemoglobin, arterial oxygen saturation, blood pressure, heart rate) which may not accurately reflect inadequacy of tissue oxygen delivery.
\end{abstract}

\begin{abstract}
Author contributions Gregory M.T. Hare designed the research, performed the research, contributed novel intellectual input, analyzed the data, and wrote the paper. Alexander $M u$ performed the research, contributed novel intellectual input, and analyzed the data. Alexander Romaschin designed the research, performed the research,

contributed novel intellectual input, and analyzed the data. Nadine Shehata designed the research, performed the research, contributed novel intellectual input, and analyzed the data. W. Scott Beattie designed the research, performed the research, contributed novel intellectual input, analyzed the data, and wrote the paper. C. David Mazer designed the research, performed the research, contributed novel intellectual input, analyzed the data, and wrote the paper. Albert K.Y. Tsui contributed novel intellectual input, analyzed the data, and wrote the paper.
\end{abstract}

G. M. T. Hare, MD, PhD ( $₫)$ · A. Mu, MD .

A. K.-Y. Tsui, PhD - C. D. Mazer, MD

Department of Anesthesia, Keenan Research Centre

in the Li Ka Shing Knowledge Institute, St. Michael's Hospital,

University of Toronto, 30 Bond Street, Toronto,

ON M5B 1W8, Canada

e-mail: hareg@smh.ca

G. M. T. Hare, MD, PhD · A. K.-Y. Tsui, $\mathrm{PhD}$.

C. D. Mazer, MD

Department of Physiology, University of Toronto, Toronto,

ON, Canada

\section{A. Romaschin, MD}

Department of Laboratory Medicine and Pathobiology,

St. Michael's Hospital, University of Toronto,

Toronto, ON, Canada
Based on experimental studies, we hypothesized that anemia-induced tissue hypoxia activates adaptive mechanisms which promote local vascular nitric oxide $(N O)$ production to improve tissue perfusion and survival during acute anemia. Hemoglobin $(\mathrm{Hb})$ oxidation to methemoglobin (MetHb) may be a byproduct of such local NO production. Therefore, we tested the hypothesis that MetHb is a biomarker of hypoxic-anemic stress during acute hemodilution associated with cardiopulmonary bypass.

Methods With institutional ethics approval, routine laboratory arterial blood gas and co-oximetry values were obtained from 295 patients undergoing heart surgery during February 1 to September 30, 2010, and the values were assessed retrospectively. All samples with an arterial oxygen saturation value $\geq 90 \%$ were included $(n=1,421)$. The maximal change in $\mathrm{Hb}$ associated with hemodilution on cardiopulmonary bypass was determined within $48 \mathrm{hr}$ of surgery $(n=180)$. A chart review was performed to determine the incidence of RBC transfusion and exogenous nitrate administration. All anonymous data were analyzed by linear regression to determine the relationship between

N. Shehata, MD

Department of Medicine, Li Ka Shing Knowledge

Institute in the Keenan Research Centre,

University of Toronto, Toronto, ON, Canada

N. Shehata, MD

Division of Hematology, St. Michael's Hospital,

Canadian Blood Services, Central Ontario Region,

Toronto, ON, Canada

W. S. Beattie, MD, PhD

Department of Anesthesia, Toronto General Hospital,

University Health Network, University of Toronto,

Toronto, ON, Canada 
Hb and MetHb. A Wilcoxon Signed Rank Test and Student's t test were used to determine changes in $\mathrm{Hb}, \mathrm{MetHb}$, and carboxyhemoglobin (CarboxHb) levels. All data are presented as mean and significance was assigned at $P<0.05$.

Results A significant decrease in $H b\left[118\right.$ (20) $g \cdot L^{-1} \mathrm{vs}$ 94 (18) $\left.g \cdot L^{-1}\right]$ was associated with an increase in MetHb [0.88 (0.22)\% vs $0.95(0.24) \%](P<0.001$ for both), but not CarboxHb [1.08 (0.47)\% vs 1.08 (0.49)\%]. Regression analysis revealed a significant relationship between the change in $\mathrm{Hb}$ and MetHb $(F=40.3 ; P<0.001)$ but not between the change in $\mathrm{Hb}$ and CarboxyHb $(F=0.2$; $P=0.694)$. This correlation was not influenced by $R B C$ transfusion or exogenous nitrate use.

Conclusions $A$ negative correlation was observed between the change in $\mathrm{Hb}$ and MetHb in patients undergoing cardiac surgery and cardiopulmonary bypass. These data support the previously unreported hypothesis that MetHb may be a marker of anemic stress associated with reduced tissue perfusion during acute hemodilution in humans. Further prospective studies are needed to determine if these changes in MetHb are linked to adverse outcomes in patients undergoing cardiac surgery.

\section{Résumé}

Objectif La transfusion de globules rouges allogéniques est l'un des principaux traitements de l'anémie aiguë secondaire à une perte sanguine et au remplissage liquidien en salle d'opération. La décision de transfuser du sang repose essentiellement sur des marqueurs biologiques intermédiaires (hémoglobine, saturation en oxygène du sang artériel, pression artérielle, fréquence cardiaque) qui pourraient ne pas refléter avec précision l'insuffisance d'apport d'oxygène aux tissus. ‘̀ partir d'études expérimentales nous avons fait l'hypothèse qu'une hypoxie tissulaire induite par l'anémie active des mécanismes adaptatifs qui encouragent la production locale d'oxyde nitrique (NO) vasculaire pour améliorer la perfusion tissulaire et la survie pendant l'anémie aiguë. La méthémoglobine (MétHb), résultant de l'oxydation de l'hémoglobine $(\mathrm{Hb})$, peut être un sous-produit de cette production locale de NO. Nous avons donc testé l'hypothèse que la MétHb est un biomarqueur du stress anémique/hypoxique survenant au cours de l'hémodilution aiguë associée à la circulation extracorporelle.

Méthodes Avec l'approbation du comité d'éthique de l'établissement, les résultats de tests de laboratoire de routine des gaz artériels du sang et d'une cooxymétrie ont été collectés auprès de 295 patients subissant une chirurgie cardiaque entre le $1^{\text {er }}$ février et le 30 septembre 2010; les valeurs ont été évaluées de façon rétrospective. Tous les échantillons dont la saturation en oxygène du sang artériel était $\geq 90 \%$ ont été inclus $(n=1421)$. La variation maximum du taux d'hémoglobine associée à l'hémodilution au cours de la circulation extracorporelle a été déterminée dans les 48 heures de l'intervention chirurgicale $(n=180)$. Les dossiers ont été analysés pour connaitre l'incidence de la transfusion de globules rouges et de l'administration de dérivés nitrés exogènes. Toutes les données anonymes ont été analysées par régression linéaire afin de déterminer la relation existant entre $\mathrm{Hb}$ et MétHb. Un test des rangs signés de Wilcoxon et un test t de Student ont permis de déterminer les variations d'Hb, de MétHb et de carboxyhémoglobine (CoHb). Toutes les données sont présentées sous forme de moyennes et la signification était atteinte pour $P<0,05$.

Résultats Une diminution significative de l'Hb [118 (20) $g \cdot L^{-1}$ contre 94 (18) $\left.g \cdot L^{-1}\right]$ a été associée à une augmentation de la MétHb [0,88 $(0,22) \%$ contre 0,95 $(0,24) \%](P<0,001$ pour les deux), mais pas de la $\mathrm{CoHb}$ [1,08 (0,47) \% contre 1,08 (0,49) \%]. L'analyse de régression a révélé une relation significative entre les variations d'Hb et de $\mathrm{MetHb}(F=40,3 ; \mathrm{P}<0$,001) mais pas entre les variations d'Hb et de $\mathrm{CoHb}(F=0,2$; $P=0,694)$. Cette corrélation n'a pas été influencée par les transfusions de globules rouges ou l'utilisation de dérivés nitrés exogènes.

Conclusions Une correlation négative a été observée entre les variations d'Hb et de MétHb chez des patients subissant une chirurgie cardiaque et une circulation extracorporelle. Ces données confortent l'hypothèse antérieure non publiée selon laquelle la méthémoglobine pourrait être un marqueur $d u$ stress anémique associé à une perfusion tissulaire réduite au cours d'une hémodilution aiguë chez l'humain. D'autres études prospectives sont nécessaires pour déterminer si ces variations de la MétHb sont liées à des résultats délétères chez des patients subissant une chirurgie cardiaque.

A number of clinical studies have shown that preoperative anemia and acute hemodilution are independent risk factors for increased mortality in cardiac and non-cardiac surgery. ${ }^{1-3}$ The recent finding that mild and moderate cases of anemia are also associated with increased mortality in patients undergoing cardiac and non-cardiac surgery makes this a critically important area of anesthesia research. ${ }^{4,5}$ Experimental studies have shown that both hypoxic and nonhypoxic mechanisms may contribute to anemia-induced organ injury and mortality. ${ }^{3,6,7}$ The complex nature of the cellular mechanisms involved may explain why anemiainduced mortality is not necessarily improved by therapies which increase blood oxygen content, including red blood cell (RBC) transfusions, ${ }^{8,9}$ use of erythropoiesis stimulating agents (ESAs), ${ }^{10}$ or hemoglobin-based oxygen carriers (HBOCs). ${ }^{11}$ Each of these strategies is capable of increasing blood oxygen content but may not increase tissue oxygen 
delivery. Indeed, some of these treatment strategies (transfusion, HBOCs) may limit tissue perfusion by reducing nitric oxide (NO) bioavailability, thereby increasing tissue hypoxia and mortality. These findings underscore the need for a fundamental understanding of the cellular mechanisms involved.

The lack of an early clinical biomarker of "anemic stress" has greatly impaired our ability to develop effective strategies to improve patient outcomes. As recently stated by one of the pioneers of anemia research, Dr. R.B. Weiskopf, "We have no clinical measures that let us know of impending insufficient oxygenation as anemia progresses". ${ }^{12}$ Toward achieving this goal, we have developed experimental models to define the adaptive mechanisms which maintain oxygen homeostasis during acute anemia. Our research has shown that increased NO production by nitric oxide syntheses (NOSs) may be an important survival mechanism in acute anemia. ${ }^{3,13,14} \mathrm{We}$ have shown that deficiency of neuronal NOS (nNOS) is associated with increased mortality in a model of hemodilutional anemia, such that mice lacking nNOS die at a mean hemoglobin $(\mathrm{Hb})$ value of $35 \mathrm{~g} \cdot \mathrm{L}^{-1}$, a level that is significantly higher than nNOS replete mice or humans $\left(\sim 25 \mathrm{~g} \cdot \mathrm{L}^{-1}\right){ }^{7,15} \mathrm{In}$ search of a clinical biomarker of NOS activation during anemia, we have hypothesized that increased nNOS-derived NO promotes a tissue-plasma NO gradient that favours the oxidation of $\mathrm{Hb}$ to MetHb, as shown by the negative correlation between increasing MetHb and decreasing $\mathrm{Hb}$ in experimental models of anemia (Fig. 1). ${ }^{3}$

In addition, a number of mechanisms have been proposed to explain how local NO production can regulate vascular tone in "hypoxic" vascular beds (Fig. 2). In one of these proposed mechanisms, MetHb is a reactive intermediate in the production of S-nitrosylated $\mathrm{Hb}(\mathrm{SNO}-\mathrm{Hb})$; a form of $\mathrm{Hb}$ that may subsequently release $\mathrm{NO}$ in hypoxic vascular beds. ${ }^{16,17}$ Experimental data in support of another proposed mechanism suggest that the stable NO metabolite nitrite $\left(\mathrm{NO}_{2}^{-}\right)$may provide a physiological source of bioactive NO by deoxygenated hemoglobin $(\operatorname{deoxyHb})$, which can act as a nitrite reductase under allosteric and $\mathrm{pH}$ control via the following reaction: Nitrite $\left[\mathrm{NO}_{2}{ }^{-}\right]+$ $\mathrm{deoxyHb}+\mathrm{H}^{+} \rightarrow \mathrm{NO}+\mathrm{MetHb}+\mathrm{HO}^{-} .{ }^{18-22}$ In either case, MetHb may be a biomarker of increased NO production and/or decreased oxygen saturation in local vascular beds. These proposed mechanisms may be particularly favoured during anemia since local production of $\mathrm{NO}$ would be supported by an increase in tissue oxyHb extraction which is known to occur in anemic vascular beds. ${ }^{23,24}$ For example, in the brain, acute anemia increases $\mathrm{Hb} \mathrm{O}_{2}$ extraction from $\sim 30 \%\left(\mathrm{Hb} \sim 140 \mathrm{~g} \cdot \mathrm{L}^{-1}\right)$ to $\sim 50 \%\left(\mathrm{Hb} \sim 50 \mathrm{~g} \cdot \mathrm{L}^{-1}\right),{ }^{23}$ while brain microvascular $\mathrm{PO}_{2}$ decreases from $\sim 70$ to $\sim 50 \mathrm{mmHg}$. ${ }^{6,7}$ As such, methemoglobin (MetHb) production may be favoured in anemic vascular beds.

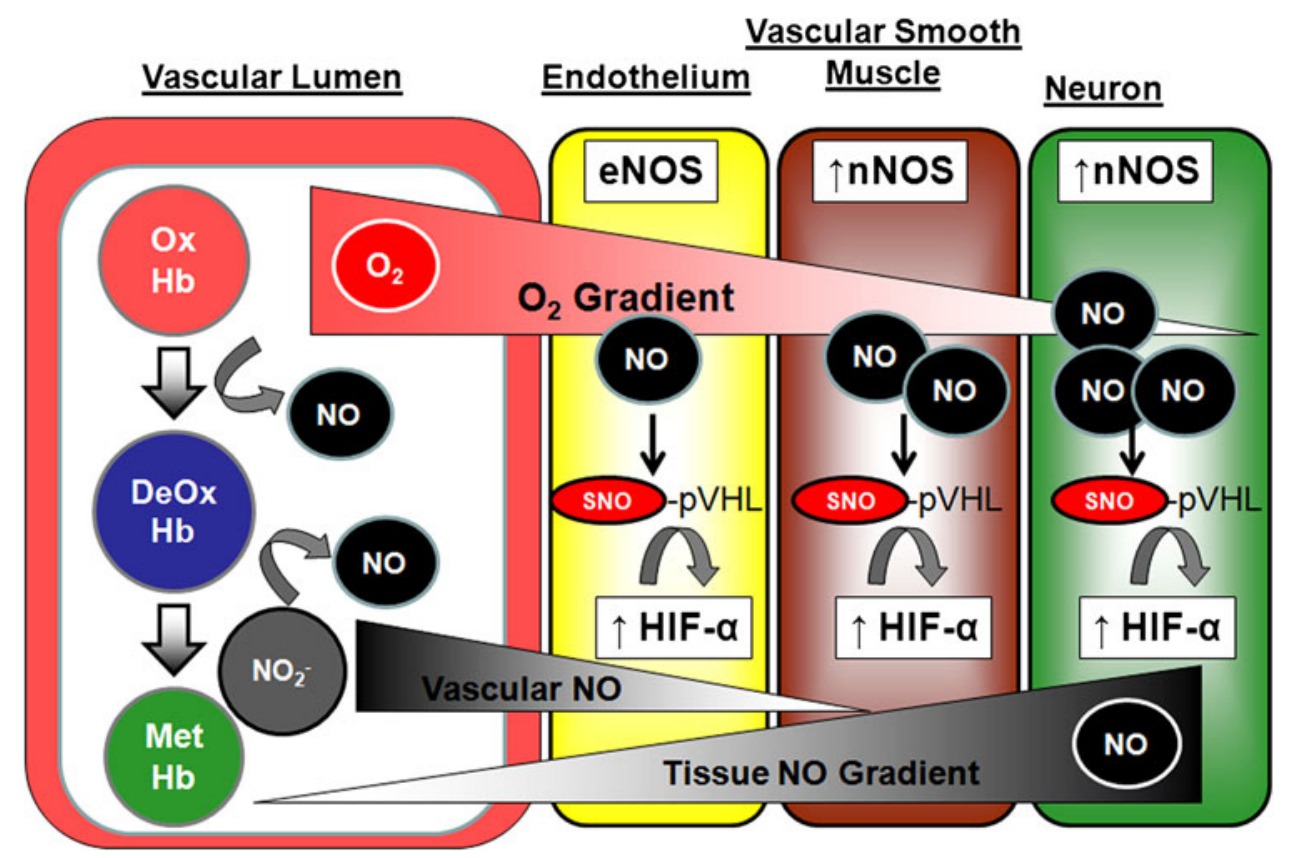

Fig. 1 Schematic representation of the mechanism by which anemia may lead to up-regulation of perivascular nitric oxide synthase (NOS) and increased nitric oxide (NO) signalling. Anemia increases NOSderived nitric oxide (NO), which can stabilize hypoxia inducible factor (HIF) in tissues by S-nitrosylation (SNO) of the von HippelLindau protein (pVHL) to activate adaptive cellular mechanisms. ${ }^{7}$
Increased tissue NOS activity generates tissue to blood nitric oxide (NO) gradient, which promotes NO diffusion into the vascular lumen to cause local vasodilation and oxidize hemoglobin $(\mathrm{Hb})$ to methemoglobin (MetHb). In addition, local conversion of nitrite $\left(\mathrm{NO}_{2}{ }^{-}\right)$to $\mathrm{NO}$ by deoxyhemoglobin (DeoxyHb) can promote vasodilation via a blood to tissue NO gradient 
Fig. 2 Mechanism by which nitric oxide (NO) may influence cellular biology and methemoglobin formation by: 1) S-nitrosylation $(\mathrm{SNO})$ of globin cycteine (Cys $\beta 93)$ on hemoglobin $^{42}$; 2) SNOmodification of circulating proteins $^{43}$; 3) deoxyhemoglobin (DeoxyHb) reduction of nitrite $\left(\mathrm{NO}_{2}{ }^{-}\right)$to methemoglobin $(\mathrm{MetHb})^{18}$; 4) free radicalmediated formation of MetHb and protein nitration ${ }^{44,45}$; and 5) redox-mediated protein SNOmodifications ${ }^{46}$

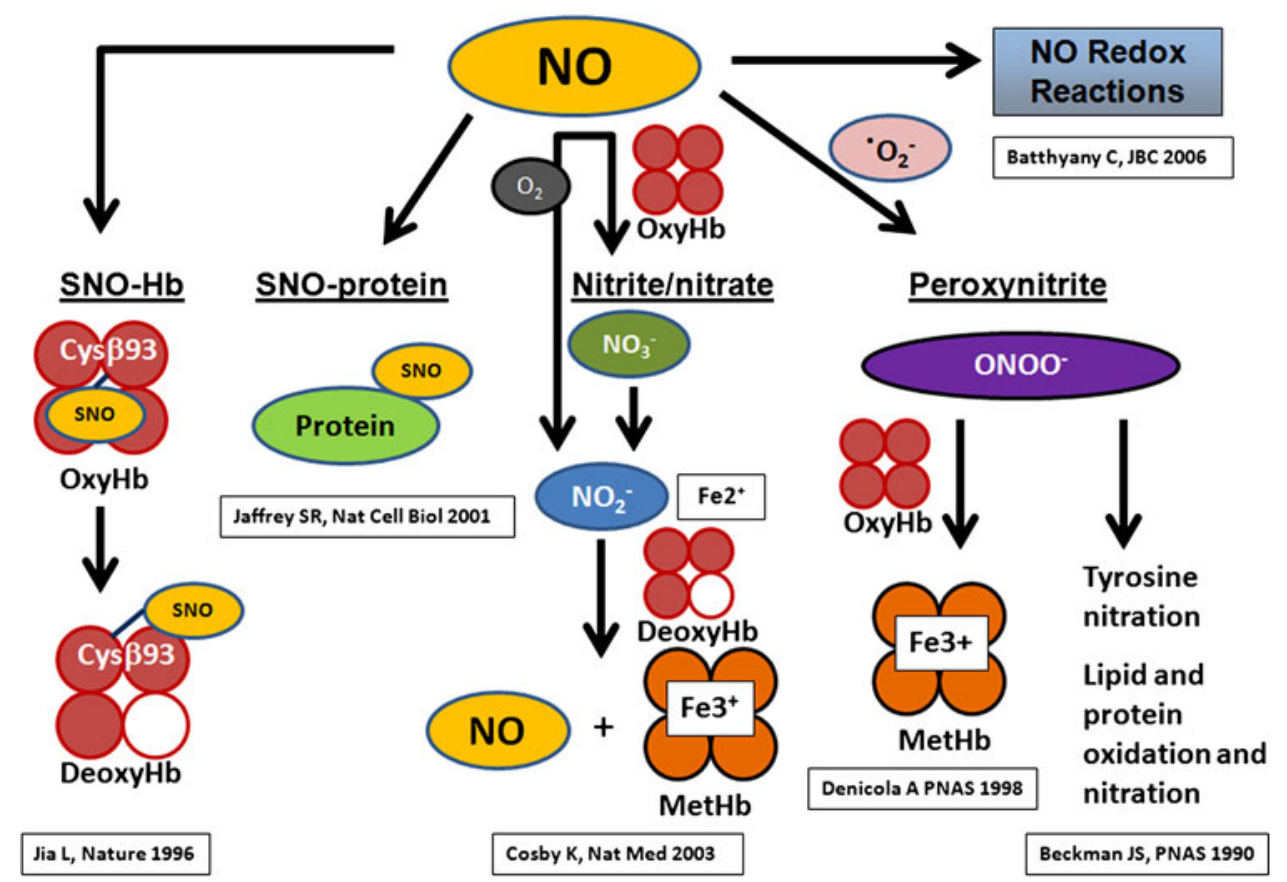

patients with pre-existing severe anemia. A second sample was then identified as the maximal change in $\mathrm{Hb}$ within the next $48 \mathrm{hr}$. This strategy was taken to obtain a pair of measurements for each patient that corresponded to a drop in $\mathrm{Hb}$ associated with hemodilution on cardiopulmonary bypass and/or surgical blood loss and fluid resuscitation. One hundred and eighty paired samples were detected in 180 patients. A subsequent chart review was used to obtain the incidence of transfusion (red blood cells, plasma, platelets, cryopreciptitate) and exogenous nitrate use. Prior to analysis, the data were assigned an independent identification number and any personal or hospital identification was removed.

Hemoglobin species are measured by co-oximeters (Radiometer ABL 800 Flex, Radiometer, Copenhagen, Denmark) which are calibrated every three months against an oxygenated (saturated) whole blood standard prepared by the manufacturer. The $\mathrm{Hb}$ value is determined by the manufacturer using a $\mathrm{HiCN}$ spectrophotometric reference method using a filter calibrated against the NIST SRM 930D filter (National Institute of Standards and Technology). Quality control material with validated and assigned target values for $\mathrm{Hb}, \mathrm{MetHb}$, and carboxyhemoglobin (CarboxyHb) is analyzed three times daily. Methemoglobin and CarboxyHb measurements are calibrated against the total hemoglobin concentration. With respect to MetHb measurements, daily control samples were run at levels of $10 \%, 5 \%$, and $2 \%$. At the $2 \%$ level, the standard deviation is $<0.001 \%$.

Statistics

A sample size estimate was based on experimental data in animals which showed that a negative correlation was 
observed with 120 paired measurements. Therefore, we estimated that at least this number of paired samples would be needed in humans. We obtained these data from patients undergoing cardiopulmonary bypass in 2010. Data were then assessed in terms of the total and change in hemoglobin, MetHb, and CarboxHb for each pair. Paired data were assessed by a Wilcoxon Signed Rank Test, and differences in mean nadir MetHb were assessed by Student's $t$ test. Linear regression analysis was performed for change in hemoglobin vs MetHb and CarboxyHb, respectively.

\section{Results}

All samples were from arterial blood gases as shown by the clinical record and the $\mathrm{S}_{\mathrm{a}} \mathrm{O}_{2}$ cut off of $>90 \%$. When all samples were assessed from 295 patients, a significant correlation was observed between the total hemoglobin and MetHb $(n=1,421$ samples; $\mathrm{F}=75.4 ; P<0.001)$ and between the change in $\mathrm{Hb}$ and $\mathrm{MetHb}(n=1,392$ samples; $\mathrm{F}=258.4$;
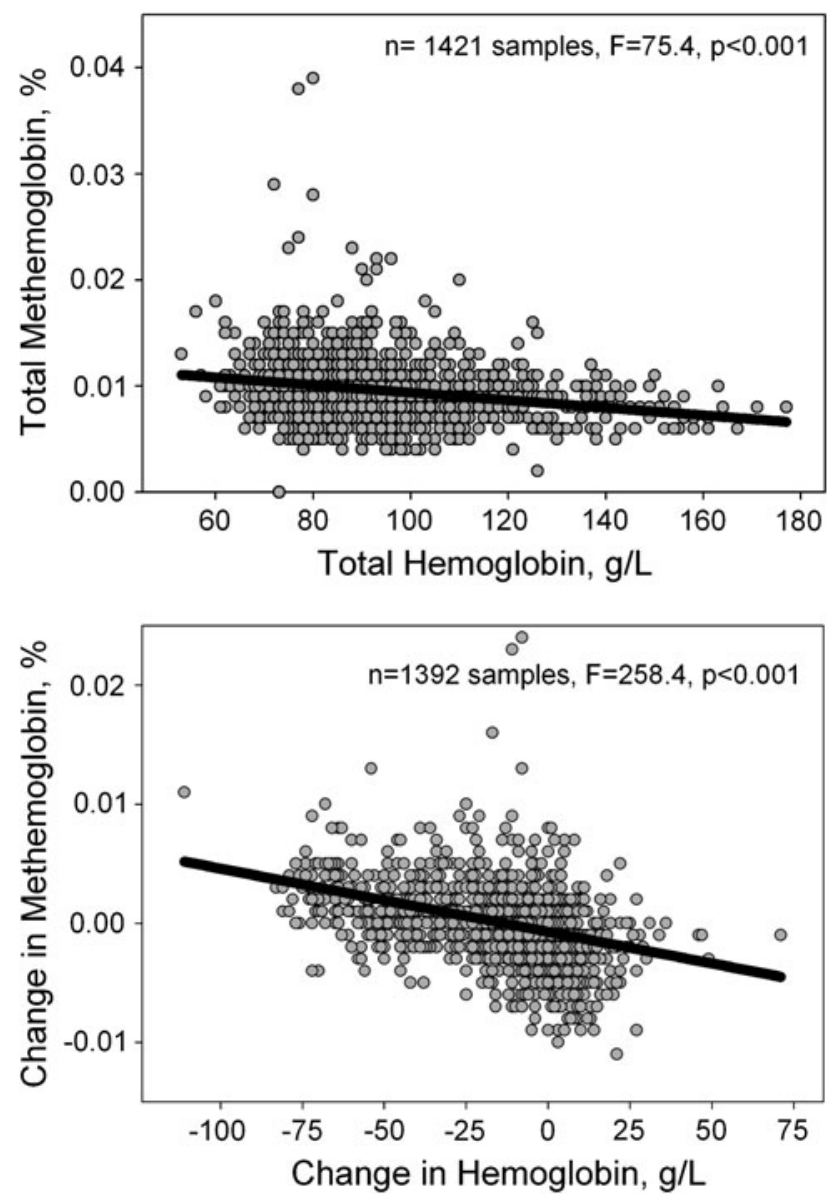

Fig. 3 Relationships between total and change in hemoglobin $(\mathrm{Hb})$ and methemoglobin (MetHb) (upper panel) and changes in $\mathrm{Hb}$ and MetHb (lower panel) in patients undergoing heart surgery with cardiopulmonary bypass $(P<0.001$ for both $)$
$P<0.001$ ) (Fig. 3). With subsequent screening by hemoglobin $>90 \mathrm{~g} \cdot \mathrm{L}^{-1}\left(1^{\text {st }}\right.$ Sample $)$ and identifying the greatest change in hemoglobin within $48 \mathrm{hr}$ ( $2^{\text {nd }}$ Sample), 180 paired data points were obtained. In this data set, a significant decrease in hemoglobin [118 (20) $\mathrm{g} \cdot \mathrm{L}^{-1}$ vs 94 (18) $\left.\mathrm{g} \cdot \mathrm{L}^{-1}\right]$ was associated with an increase in MetHb [0.88 $(0.22) \%$ vs 0.95 (0.24)\%], but not CarboxyHb [1.08 (0.47)\% vs $1.08(0.49) \%]$ (Fig. 4). Subsequent regression analysis revealed a significant relationship between the change in $\mathrm{Hb}$ and $\mathrm{MetHb}(n=180$ samples; $\mathrm{F}=40.3 ; P<0.001$ ) (Fig. 5) but not between the change in $\mathrm{Hb}$ and CarboxyHb $(\mathrm{F}=0.2 ; P=0.694)$. This relationship was maintained in those patients who received a $\mathrm{RBC}$ transfusion $(n=62 ; \mathrm{F}=16.2 ; P<0.001)$ and in those who did not receive a $\mathrm{RBC}$ transfusion $(n=118 ; \mathrm{F}=28.4$; $P<0.001$ ). When assessed in terms of the nadir hemoglobin, only patients with a $\mathrm{Hb}$ value $<90$ showed a significant increase in MetHb $(P<0.001)$ (Fig. 6).
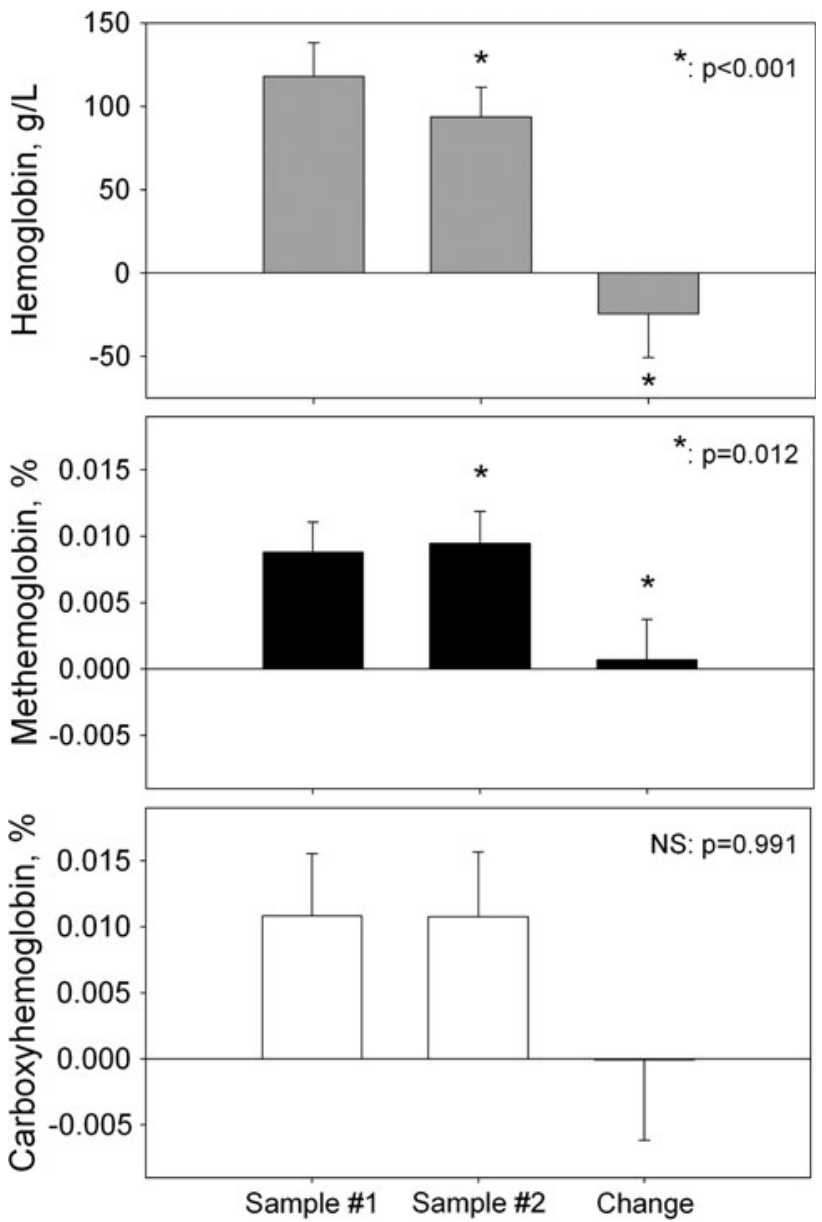

Fig. 4 Change in hemoglobin, methemoglobin, and carboxyhemoglobin [mean (standard deviation)] between the first preoperative (hemoglobin $[\mathrm{Hb}]>90 \mathrm{~g} \cdot \mathrm{L}^{-1}$ ) and second hemoglobin sample (largest change in $\mathrm{Hb}$ within $48 \mathrm{hr}$ ) in patients undergoing heart surgery and cardiopulmonary bypass. Notice that the hemoglobin decreased overall while methemoglobin increased. Carboxyhemoglobin was unchanged 


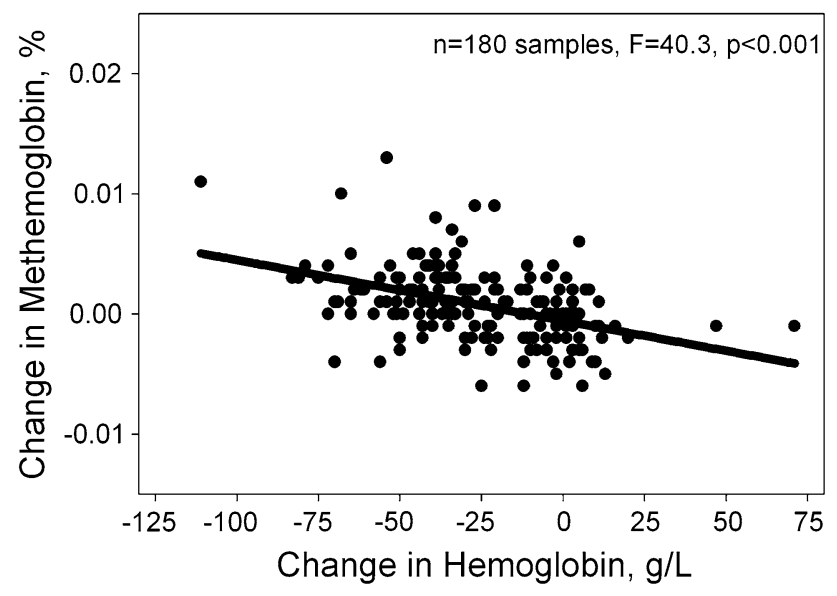

Fig. 5 Relationship between the change in hemoglobin and methemoglobin in 180 paired samples from 180 patients from the first (hemoglobin $[\mathrm{Hb}]>90 \mathrm{~g} \cdot \mathrm{L}^{-1}$ ) to the second hemoglobin sample (largest change in $\mathrm{Hb}$ within $48 \mathrm{hr}$ )

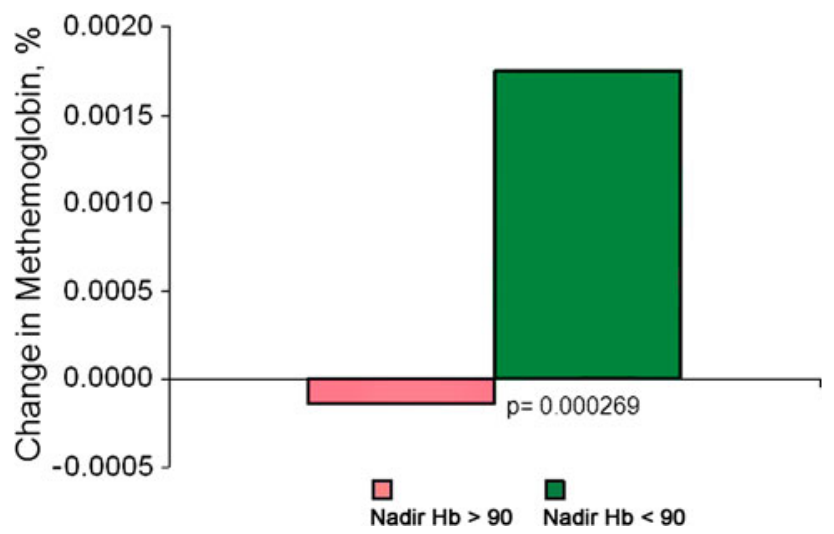

Fig. 6 Relationship between methemoglobin levels when the nadir hemoglobin was above or below the threshold of $90 \mathrm{~g} \cdot \mathrm{L}^{-1}$

Of the 180 patients selected for final assessment, the surgical procedures that were performed included: 1) isolated coronary artery bypass grafting $(\mathrm{CABG})(n=115)$; single or double valve replacement $(n=39)$; aortic aneurism repair $(n=7)$; combined CABG-valve replacement $(n=13)$; and other procedures, including septal defect repairs, pericardiectomy, and atrial myxoma excision $(n=6)$. Data showing the frequency of transfusion of blood products in the 180 patient cohort are presented in the Table. Sixty-two (34\%) of these 180 patients received a RBC transfusion, most of which were given after the nadir $\mathrm{Hb}$ had been reached. Most of these patients received the RBC transfusion after leaving the operating room (36 of 62 ). Only 26 patients received a RBC transfusion in the operating room. Preoperative use of long-acting nitrates was recorded in $13(7 \%)$ of 180 patients. None of these patients received intraoperative nitroglycerine and $16(9 \%)$
Table Record of blood product transfusion

\begin{tabular}{llll}
\hline $\begin{array}{l}\text { Product } \\
\text { transfused } \\
(180 \text { patients })\end{array}$ & $\begin{array}{l}\text { Number of } \\
\text { patients } \\
\text { transfused, } \\
n(\%)\end{array}$ & $\begin{array}{l}\text { Number of } \\
\text { units } \\
\text { transfused }\end{array}$ & $\begin{array}{l}\text { Number of units } \\
\text { per transfused } \\
\text { patient }\end{array}$ \\
\hline Red blood cells & $62(34)$ & 176 & 2.8 \\
Plasma & $19(11)$ & 63 & 3.3 \\
Platelets & $18(10)$ & 24 & 1.3 \\
Cryoprecipitate & $11(6)$ & 95 & 8.6 \\
\hline
\end{tabular}

of 180 patients received postoperative nitrate therapy, primarily for treatment of hypertension.

\section{Discussion}

These retrospective data support the hypothesis that MetHb may be a useful biomarker of anemic stress in humans. We showed that a reduction in hemoglobin concentration in patients undergoing cardiac surgery and cardiopulmonary bypass is associated with an increase in MetHb levels. This relationship was not altered by RBC transfusion or exogenous nitrate use. A similar relationship did not occur for CarboxHb which served as an internal negative control. The proposed mechanism for increased MetHb may include NO-mediated $\mathrm{Hb}$ oxidation or reduction of nitrite $\left(\mathrm{NO}_{2}{ }^{-}\right)$ by $\mathrm{DeoxyHb}$, as suggested by experimental and clinical studies. ${ }^{3,18-22}$ It will be important to assess these changes in subsequent studies to determine if the increase in MetHb is reflective of activated adaptive mechanisms $(\mathrm{nNOS})^{7}$ and/ or increased $\mathrm{OxyHb}$ desaturation to DeoxyHb and tissue hypoxia $^{18-22}$ during acute hemodilutional anemia.

Future prospective studies are planned to establish whether the observed increase in MetHb is predictive of adverse clinical outcomes. These studies will be needed to assess the clinical impact of: 1) postponing surgery to treat anemia and prevent adverse outcomes; or 2) utilizing the rise in MetHb as an appropriate trigger for transfusion to reduce adverse outcomes in cardiac and non-cardiac surgery. In a recently published Phase 1 trial (TRICS 1), the feasibility of completing a transfusion threshold study $\left(80 \mathrm{~g} \cdot \mathrm{L}^{-1}\right.$ vs $\left.100 \mathrm{~g} \cdot \mathrm{L}^{-1}\right)$ showed twice the number of ischemia-related events in the low $\mathrm{Hb}$ threshold group. ${ }^{27}$ Although the study was not powered to assess differences in patient outcomes, the data raise the frequently posed clinical question regarding whether cardiac surgical patients require a higher $\mathrm{Hb}$ threshold. Assessment of MetHb level is planned as a component of the ongoing Phase 2 study (TRICS 2). These future studies are required to establish the importance of MetHb as a functional biomarker for anemic stress, potentially marking the threshold of increased risk of hypoxic tissue injury during acute hemodilution and anemia. 
With respect to the selection of appropriate transfusion triggers, the authors do not regard any one measurement as a sole marker for transfusion ( $\mathrm{Hb}, \mathrm{MetHb}$ etc). The clinical decision to transfuse RBCs is always based on a number of parameters, including patient co-morbidities, changes in physiological parameters, type of surgery, patient consent for treatment, and hemoglobin concentration. The purpose of the current study was to assess whether increased MetHb levels could reflect activation of adaptive physiological mechanisms indicative of tissue hypoxia during anemia as suggested by our basic science research. ${ }^{3,4,6}$ The potential biological significance of this approach is emphasized by two possible mechanisms by which increased MetHb production is favoured during anemia. First, the adaptive increase in nNOS during anemia promotes organism survival in part by activating hypoxic cellular mechanisms in anemic mice. ${ }^{7}$ In this case, MetHb is a byproduct of nNOSderived NO (Fig. 1). Second, the increase in DeoxyHb in local vascular beds, secondary to increased oxygen extraction, ${ }^{23,24}$ would favour the production of NO from nitrite with MetHb as the byproduct (Fig. 2). ${ }^{18-22}$ In both cases, the increase in MetHb may signify activation of adaptive mechanisms, likely triggered by inadequate oxygen delivery and tissue hypoxia.

The importance of NOS-derived NO as a signalling mechanism for adaptive cardiovascular responses has been extensively reviewed. ${ }^{28-31}$ Nitric oxide signalling is known to regulate cardiac output and systemic vascular resistance via direct action at the cardiac myocyte and vascular smooth muscle and by regulation of centrally mediated changes in autonomic function. ${ }^{28-31}$ In a model of acute anemia, nNOS protects against mortality, ${ }^{7}$ providing strong rational to pursue the current line of clinical research.

The importance of maintaining NO signalling at times of hemodynamic stress has been shown indirectly by experimental and clinical studies which have shown adverse outcomes in association with therapy that limits NO availability. For example, NOS inhibition impairs cerebral blood flow responses in anemic animals and those undergoing hemodilution during cardiopulmonary bypass. ${ }^{32,33}$ When systemic NOS inhibitors were administered to increase mean arterial pressure and improve clinical outcomes in septic patients, a surprising increase in mortality was observed. ${ }^{34}$ Finally, the use of HBOCs to improve oxygen delivery has resulted in the paradoxical finding of increased incidence of myocardial injury and mortality. These adverse outcomes may have been due to reduced NO bioavailability. ${ }^{11,35}$ Thus, generalized NOS inhibition or NO scavenging has been associated with adverse cardiovascular outcomes and increased mortality.

Experimental models of acute hemodilution have shown that anemia results in an increase in both neuronal and inducible NOS (nNOS and iNOS), possibly in response to anemia-induced tissue hypoxia. ${ }^{3,13,14}$ These tissue responses to hypoxia have been identified since early metazoan development ${ }^{36}$ and have been shown to support survival during acute anemia. ${ }^{7}$ The link between increased NOS and MetHb has been derived by our analysis of experimental studies assessing acute changes in hemoglobin and $\mathrm{MetHb}$ during hemodilution anemia. ${ }^{3}$ In these models, a characteristic and proportional increase in plasma MetHb was observed with decreasing hemoglobin levels. We chose to assess whether a similar $\mathrm{Hb} / \mathrm{MetHb}$ relationship occurred in humans. To do this, we chose to study patients undergoing cardiopulmonary bypass, as all of these patients experience a consistent and sudden drop in hemoglobin by hemodilution. The current data are encouraging and support future studies to assess the $\mathrm{Hb} / \mathrm{MetHb}$ relationship in prospective studies in cardiac and non-cardiac surgery.

Under physiological conditions, most healthy individuals and patients undergoing cardiovascular surgery have baseline blood MetHb levels near $1 \%$, as shown by measurements in the current study. While the increase in MetHb levels in response to a drop in $\mathrm{Hb}$ is quite small, it occurred in proportion to the drop in $\mathrm{Hb}$, suggesting that there may be a relationship between the two changes. These levels are not clinically significant from the perspective of absolute oxygen carrying capacity of the blood. However, they may represent a true physiological signal in response to biological adaptation and hypoxic stresses associated with anemia, as described above. ${ }^{3,4,6}$ In addition to being biologically relevant, these small changes are well within the detection range of our co-oximeter, which can detect changes within a standard deviation of $0.001 \%$ (please see methods). For example, for all samples in which the MetHb increased by more than $0.001 \%(n=63$ of 180$)$, the mean MetHb increased from $0.007(0.002) \%$ to $0.011(0.002) \%$. This represents a $57 \%$ increase $(P<0.001)$. Therefore, the increase in MetHb may be small, but it has the potential of being both biologically and statistically relevant. We did not observe a relationship between changes in $\mathrm{Hb}$ and CarboxyHb, possibly because changes in CarboxyHb depend more specifically on blood carbon monoxide levels and are less influenced by redox reactions.

Although the incidence of acquired methemoglobinemia is very low, it frequently occurs in response to the use of topical anesthetic agents. ${ }^{25,26,37}$ The mechanism of anesthetic-induced methemoglobinemia is thought to occur as a result of direct oxidation of hemoglobin by amine metabolites derived from the amide-anesthetics. ${ }^{37}$ Benzocaine use appears to have the highest incidence of methemoglobinemia. ${ }^{37}$ However, many other drugs which possess oxidizing capacity can overwhelm the endogenous MetHb reductase and cause methemoglobinemia. ${ }^{25}$ In addition, direct exposure to inhaled NO can have significant impact on the systemic circulation and remote tissue perfusion via 
the action of stable NO metabolites. ${ }^{38}$ Inhaled NO can also cause elevated MetHb levels in specific clinical settings. ${ }^{39}$ Despite the rarity of clinically significant increases in $\mathrm{MetHb}$, two of the largest series of case reports have shown a high incidence of anemia in $84 \%$ and $94 \%$ of cases. ${ }^{25,26}$ In one case series, methemoglobinemia was diagnosed at blood sampling by anesthesiologists during cases in which acute blood loss prompted the measurement of the hemoglobin concentration. ${ }^{25}$ This suggests that anemia (and acute blood loss) may have been a risk factor for methemoglobinemia in a previously reported case series. This background supports the findings of the current study and supports our hypothesis that MetHb may be a biomarker of anemic stress in humans.

Methylene blue is used to treat methemoglobinemia by its ability to reduce MetHb via non-enzymatic donation of electrons $^{40}$ and by its ability to impair NO-mediated oxidation of hemoglobin. ${ }^{3}$ Methylene blue is also known for its NO binding capacity and treatment of vasoplegia associated with cardiopulmonary bypass. ${ }^{40,41}$ Taken together, these data suggest that methylene blue is a potent inhibitor of NO production/action and is also associated with a profound vasoconstricting effect. This may maintain blood pressure in the setting of profound vasoplegia associated with cardiac surgery. However, under more physiological conditions (anemia) in which systemic NO may be regarded as adaptive, the impact of NO binding by methylene blue may be detrimental.

The current study has some limitations. The retrospective nature and small sample size are identified weaknesses of this study. These data may relate only to cardiac surgical patients undergoing cardiopulmonary bypass and may not be generalized to non-cardiac surgery. The time of $\mathrm{Hb}$ sampling was not controlled in this study. The relatively small changes in MetHb levels may make this a relatively insensitive means of detecting anemia-induced changes in cardiovascular physiology. However, these measurements were within the detection limits of the co-oximeters used. The potential impact of extrinsic nitrates was assessed and found not to influence the outcome as few patients received these medications. Although RBC transfusion may influence MetHb levels, we did not observe this effect. In our study, only $26(14 \%)$ of 180 patients received RBCs at the time of surgery when the maximal change in $\mathrm{Hb}$ was recorded. The negative correlation between $\mathrm{Hb}$ and $\mathrm{MetHb}$ was maintained despite the presence or absence of a RBC transfusion. Furthermore, in 34 paired samples in which the $\mathrm{Hb}$ increased by an average of 15 (17) $\mathrm{g} \cdot \mathrm{L}^{-1}$, corresponding MetHb levels did not change [- $0.001(0.003)]$. Thus, no relationship between RBC transfusion and increased MetHb was observed.

In conclusion, these human data provide support for the hypothesis that increased MetHb levels may provide an early biomarker of anemic stress in our patients. In future studies, these changes in $\mathrm{Hb} / \mathrm{MetHb}$ need to be correlated with clinical outcomes, such as renal failure, myocardial infarction, stroke, and death. If a positive correlation is observed between changes in $\mathrm{Hb} / \mathrm{MetHb}$ and clinical outcomes, then assessment of MetHb levels may provide an early biomarker for the detection of anemia-related adverse outcomes. In addition, new methods of assessing $\mathrm{Hb}$ and $\mathrm{MetHb}$ in real time may offer a noninvasive means for assessing changes in $\mathrm{Hb} / \mathrm{MetHb}$ in our patients. ${ }^{28}$

Funding Supported by the Canadian Anesthesiologists' Society and the Departments of Anesthesia and Laboratory Medicine, St. Michael's Hospital, University of Toronto. Dr. Beattie received funding from the R. Fraser Elliot Endowment. Drs. Beattie, Hare and Mazer have Merit Award support from the Department of Anesthesia, University of Toronto.

Competing interests None declared.

\section{References}

1. Beattie WS, Karkouti K, Wijeysundera DN, Tait G. Risk associated with preoperative anemia in noncardiac surgery: a singlecenter cohort study. Anesthesiology 2009; 110: 574-81.

2. Karkouti K, Wijeysundera DN, Beattie WS. Reducing Bleeding in Cardiac Surgery (RBC) Investigators. Risk associated with preoperative anemia in cardiac surgery: a multicenter cohort study. Circulation 2008; 117: 478-84.

3. Tsui AK, Dattani ND, Marsden PA, et al. Reassessing the risk of hemodilutional anemia: some new pieces to an old puzzle. Can J Anesth 2010; 57: 779-91.

4. Hung M, Besser M, Sharples LD, Nair SK, Klein AA. The prevalence and association with transfusion, intensive care unit stay and mortality of pre-operative anaemia in a cohort of cardiac surgery patients. Anaesthesia 2011; 66: 812-8.

5. Musallam KM, Tamim HM, Richards T, et al. Preoperative anaemia and postoperative outcomes in non-cardiac surgery: a retrospective cohort study. Lancet 2011; 378: 1396-407.

6. Ragoonanan TE, Beattie WS, Mazer CD, et al. Metoprolol reduces cerebral tissue oxygen tension after acute hemodilution in rats. Anesthesiology 2009; 111: 988-1000.

7. Tsui AK, Marsden PA, Mazer CD, et al. Priming of hypoxiainducible factor by neuronal nitric oxide synthase is essential for adaptive responses to severe anemia. Proc Natl Acad Sci USA 2011; 108: 17544-9.

8. Hebert PC, Wells G, Blajchman MA, et al. A multicenter, randomized, controlled clinical trial of transfusion requirements in critical care. Transfusion Requirements in Critical Care Investigators, Canadian Critical Care Trials Group. N Engl J Med 1999; 340: 409-17.

9. Koch CG, Li L, Sessler DI, et al. Duration of red-cell storage and complications after cardiac surgery. N Engl J Med 2008; 358: 1229-39.

10. Pfeffer MA, Burdmann EA, Chen CY, et al. A trial of darbepoetin alfa in type 2 diabetes and chronic kidney disease. N Engl J Med 2009; 361: 2019-32.

11. Natanson C, Kern SJ, Lurie P, Banks SM, Wolfe SM. Cell-free hemoglobin-based blood substitutes and risk of myocardial infarction and death: a meta-analysis. JAMA 2008; 299: 2304-12. 
12. Weiskopf RB. Emergency transfusion for acute severe anemia: a calculated risk. Anesth Analg 2010; 111: 1088-92.

13. McLaren AT, Marsden PA, Mazer CD, et al. Increased expression of HIF-1 alpha, nNOS, and VEGF in the cerebral cortex of anemic rats. Am J Physiol Regul Integr Comp Physiol 2007; 292: R403-14.

14. McLaren AT, David MC, Zhang H, Liu E, Mok L, Hare GM. A potential role for inducible nitric oxide synthase in the cerebral response to acute hemodilution. Can J Anesth 2009; 56: 502-9.

15. Shander A, Javidroozi M, Ozawa S, Hare GM. What is really dangerous - anaemia or transfusion? Br J Anaesth 2011; 107: i41-59.

16. Luchsinger BP, Rich EN, Gow AJ, Williams EM, Stamler JS, Singel DJ. Routes to S-nitrosohemoglobin formation with heme redox and preferential reactivity in the beta subunits. Proc Natl Acad Sci USA 2003; 100: 461-6.

17. Angelo M, Singel DJ, Stamler JS. An S-nitrosothiol (SNO) synthase function of hemoglobin that utilizes nitrite as a substrate. Proc Natl Acad Sci USA 2006; 103: 8366-71.

18. Cosby K, Partovi KS, Crawford JH, et al. Nitrite reduction to nitric oxide by deoxyhemoglobin vasodilates the human circulation. Nat Med 2003; 9: 1498-505.

19. Crawford JH, Isbell TS, Huang Z, et al. Hypoxia, red blood cells, and nitrite regulate NO-dependent hypoxic vasodilation. Blood 2006; 107: 566-74.

20. Gladwin MT, Raat NJ, Shiva $S$, et al. Nitrite as a vascular endocrine nitric oxide reservoir that contributes to hypoxic signaling, cytoprotection, and vasodilation. Am J Physiol Heart Circ Physiol 2006; 291: H2026-35.

21. Hobbs AJ, Gladwin MT, Patel RP, Williams DL, Butler AR. Haemoglobin: NO transporter, NO inactivator or NOne of the above? Trends Pharmacol Sci 2002; 23: 406-11.

22. Huang Z, Shiva S, Kim-Shapiro DB, et al. Enzymatic function of hemoglobin as a nitrite reductase that produces NO under allosteric control. J Clin Invest 2005; 115: 2099-107.

23. van Bommel J, Trouwborst A, Schwarte L, Siegemund M, Ince C, Henny $C$. Intestinal and cerebral oxygenation during severe isovolemic hemodilution and subsequent hyperoxic ventilation in a pig model. Anesthesiology 2002; 97: 660-70.

24. Weiskopf RB, Viele MK, Feiner J, et al. Human cardiovascular and metabolic response to acute, severe isovolemic anemia. JAMA 1998; 279: 217-21.

25. Ash-Bernal R, Wise R, Wright SM. Acquired methemoglobinemia: a retrospective series of 138 cases at 2 teaching hospitals. Medicine (Baltimore) 2004; 83: 265-73.

26. Kane GC, Hoehn SM, Behrenbeck TR, Mulvagh SL. Benzocaineinduced methemoglobinemia based on the Mayo Clinic experience from 28478 transesophageal echocardiograms: incidence, outcomes, and predisposing factors. Arch Intern Med 2007; 167: 1977-82.

27. Shehata N, Burns LA, Nathan H, et al. A randomized controlled pilot study of adherence to transfusion strategies in cardiac surgery. Transfusion 2012; 52: 91-9.

28. Mohan RM, Golding S, Heaton DA, Danson EJ, Paterson DJ. Targeting neuronal nitric oxide synthase with gene transfer to modulate cardiac autonomic function. Prog Biophys Mol Biol 2004; 84: 321-44.

29. Sears CE, Ashley EA, Casadei B. Nitric oxide control of cardiac function: is neuronal nitric oxide synthase a key component? Philos Trans R Soc Lond B Biol Sci 2004; 359: 1021-44.
30. Ward ME, Toporsian M, Scott JA, et al. Hypoxia induces a functionally significant and translationally efficient neuronal $\mathrm{NO}$ synthase mRNA variant. J Clin Invest 2005; 115: 3128-39.

31. Iadecola $C$, Beitz AJ, Renno $W, X u X$, Mayer B, Zhang $F$. Nitric oxide synthase-containing neural processes on large cerebral arteries and cerebral microvessels. Brain Res 1993; 606: 148-55.

32. Hudetz AG, Wood JD, Kampine JP. 7-Nitroindazole impedes erythrocyte flow response to isovolemic hemodilution in the cerebral capillary circulation. J Cereb Blood Flow Metab 2000; 20: 220-4.

33. Plochl W, Liam BL, Cook DJ, Orszulak TA. Cerebral response to haemodilution during cardiopulmonary bypass in dogs: the role of nitric oxide synthase. Br J Anaesth 1999; 82: 237-43.

34. Lopez A, Lorente JA, Steingrub J, et al. Multiple-center, randomized, placebo-controlled, double-blind study of the nitric oxide synthase inhibitor 546C88: effect on survival in patients with septic shock. Crit Care Med 2004; 32: 21-30.

35. Olofsson CI, Gorecki AZ, Dirksen R, et al. Evaluation of MP4OX for Prevention of perioperative hypotension in patients undergoing primary hip arthroplasty with spinal anesthesia: a randomized, double-blind, multicenter study. Anesthesiology 2011; 114: 1048-63.

36. Renshaw GM, Dyson SE. Increased nitric oxide synthase in the vasculature of the epaulette shark brain following hypoxia. Neuroreport 1999; 10: 1707-12.

37. Guay J. Methemoglobinemia related to local anesthetics: a summary of 242 episodes. Anesth Analg 2009; 108: 837-45.

38. Lang JD Jr, Teng X, Chumley $P$, et al. Inhaled NO accelerates restoration of liver function in adults following orthotopic liver transplantation. J Clin Invest 2007; 117: 2583-91.

39. Hermon MM, Burda G, Golej J, et al. Methemoglobin formation in children with congenital heart disease treated with inhaled nitric oxide after cardiac surgery. Intensive Care Med 2003; 29: 447-52.

40. Stawicki SP, Sims C, Sarani B, Grossman MD, Gracias VH. Methylene blue and vasoplegia: who, when, and how? Mini Rev Med Chem 2008; 8: 472-90.

41. Maslow AD, Stearns G, Butala P, Schwartz CS, Gough J, Singh $A K$. The hemodynamic effects of methylene blue when administered at the onset of cardiopulmonary bypass. Anesth Analg 2006; 103: 2-8.

42. Jia L, Bonaventura C, Bonaventura J, Stamler JS. S-nitrosohaemoglobin: a dynamic activity of blood involved in vascular control. Nature 1996; 380: 221-6.

43. Jaffrey $S R$, Erdjument-Bromage H, Ferris $C D$, Tempst $P$, Snyder $S H$. Protein S-nitrosylation: a physiological signal for neuronal nitric oxide. Nat Cell Biol 2001; 3: 193-7.

44. Beckman JS, Beckman TW, Chen J, Marshall PA, Freeman BA. Apparent hydroxyl radical production by peroxynitrite: implications for endothelial injury from nitric oxide and superoxide. Proc Natl Acad Sci USA 1990; 87: 1620-4.

45. Denicola A, Souza JM, Radi R. Diffusion of peroxynitrite across erythrocyte membranes. Proc Natl Acad Sci USA 1998; 95: 3566-71.

46. Batthyany C, Schopfer FJ, Baker PR, et al. Reversible posttranslational modification of proteins by nitrated fatty acids in vivo. J Biol Chem 2006; 281: 20450-63. 